\title{
Blood pyruvate concentration measured by a specific method in control subjects
}

\author{
J. LANDON, J. K. FAWCETT, AND VICTOR WYNN
}

From the Surgical Unit, St. Mary's Hospital, London

SYNOPSIS A specific method of estimating pyruvate, depending upon the oxidation of reduced nicotinamide-adenine dinucleotide in the presence of lactic dehydrogenase, has been modified to improve its accuracy. The precision of the modification, measured by duplicate analysis, was represented by a standard deviation of $0.03 \mathrm{mg} . / 100 \mathrm{ml}$. The mean recovery of added pyruvate was $99 \%$.

The mean blood pyruvate concentration in 30 fasted subjects, who had no illness known to affect pyruvate metabolism, was $0.44 \mathrm{mg} . / 100 \mathrm{ml}$. (S.D. 0.05). Blood pyruvate levels were measured at 30-minute intervals for two hours after oral or intravenous administration of glucose. The highest levels obtained in each case were about $0.4 \mathrm{mg} . / 100 \mathrm{ml}$. higher than the initial level, and were found 60 to 90 minutes after oral administration and 30 to 60 minutes after intravenous administration.

Pyruvic acid occupies a central position in intermediary metabolism, and its level in the blood is affected by many conditions. It is important that a specific and relatively rapid method for its measurement in biological solutions should be available.

The most commonly used methods of measuring pyruvate depend upon its condensation with 2,4dinitrophenylhydrazine. Several modifications have been developed (Barrenscheen and Dreguss, 1931; Lu, 1939; Bueding and Wortis, 1940; Klein, 1941; Bonting, 1955), the most popular being that of Friedemann and Haugen (1943). These methods, however, are not specific because the results are variably affected by other $\alpha$-keto acids.

Paper chromatography of the hydrazones of the $\alpha$-keto acids was introduced by Cavallini, Frontali, and Toschi (1949) for the specific measurement of pyruvate and has been used by several other workers, including Seligson and Shapiro (1952), El Hawary and Thompson (1953), and McArdle (1957). This step, however, is time consuming and may result in loss of some of the pyruvic acid hydrazone.

Specific and more rapid methods for measuring pyruvate have been introduced. These depend upon the oxidation of reduced nicotinamide-adenine dinucleotide (NADH) in the presence of lactic dehydrogenase (LDH) according to the following equation:

Received for publication 23 March 1962.

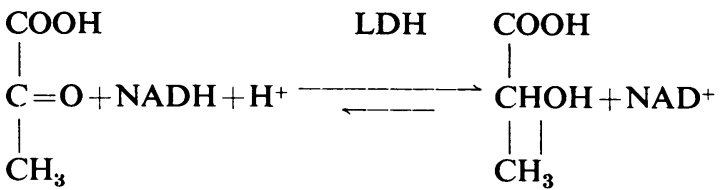

The oxidation of nicotinamide-adenine dinucleotide is measured spectrophotometrically by the change in extinction at its peak absorption of $340 \mathrm{~m} \mu$. The reaction between pyruvic acid and reduced nicotinamide adenine dinucleotide is stoichiometric. Since the equilibrium of this reaction lies far to the right (Kubowitz and Ott, 1943), the fall in extinction is proportional to the pyruvate concentration. Hess (1955) added reduced nicotinamide-adenine dinucleotide to serum and made use of the serum lactic dehydrogenase present. Other workers (Bauer, 1956; Redetzki, Bloedorn, and Bansi, 1956; Segal, Blair, and Wyngaarden, 1956) deproteinized blood immediately to inactivate its lactic dehydrogenase, and later established a buffer system with a $p \mathrm{H}$ of about 6 and added reduced nicotinamide-adenine dinucleotide and then lactic dehydrogenase to promote the reaction.

The purpose of the present paper is to report some observations on the nicotinamide-adenine dinucleotide reaction for the measurement of blood pyruvic acid. The levels in control subjects while fasting and after oral or intravenous administration of glucose are also recorded. 


\section{SUBJECTS AND PROCEDURES}

SUBJECTS Thirty subjects, 14 men and 16 women, between 16 and 74 years of age, were studied. None had any illness known to affect pyruvate metabolism, and all were ambulant and received an adequate diet.

PROCEDURES The following procedures were carried out after a fast of from 14 to 17 hours:-

Estimation of fasting levels of blood pyruvate and investigation of effect of oral glucose on blood pyruvate concentration A $50 \%$ solution of glucose $(1 \mathrm{~g} . / \mathrm{kg}$. body weight) was given orally, and blood samples were taken at 30-minute intervals for two hours for the estimation of blood pyruvate and blood sugar levels.

Investigation of effect of intravenous glucose on blood pyruvate concentration A $50 \%$ solution of glucose $(0.5 \mathrm{~g} . / \mathrm{kg}$. body weight) was injected intravenously within four minutes. Blood samples were taken at 30-minute intervals for two hours for the estimation of blood pyruvate concentration and at 15-minute intervals for the estimation of blood sugar.

Blood was taken from a vein in the forearm or antecubital fossa, usually through an indwelling needle. When an indwelling needle was used, a solution of heparin and saline was introduced between sampling to prevent clotting. The heparinized saline solution was washed out of the needle with $1 \mathrm{ml}$. of blood immediately before taking each sample.

Blood samples were not taken until several minutes after inserting the needle. The effects of hand warming, hand clenching, and venous occlusion were studied. In investigations an adequate blood flow was encouraged by warming the hand with an electric pad, hand clenching and venous occlusion being avoided.

\section{METHOD}

About $4 \mathrm{ml}$. of blood was withdrawn rapidly and transferred to a tube containing heparin. Three ml. of blood was then pipetted slowly, continuously mixing with a small rod, into $6 \mathrm{ml}$. of $0.6 \mathrm{M}$ perchloric acid in a centrifuge tube surrounded by ice and water. Manipulations were adjusted so that the interval between the midpoint of withdrawing the blood and the midpoint of adding it to the perchloric acid was as close as possible to one minute. The tube was then sealed with parafilm and the contents mixed carefully by inversion. The tube was kept at a temperature of 0 to $5^{\circ} \mathrm{C}$ until it could be centrifuged at about 3,000 r.p.m. for five to 10 minutes.

A $3 \mathrm{ml}$. portion of the supernatant was recooled to below $5^{\circ}$, mixed with $1 \mathrm{ml}$. of cooled $1.5 \mathrm{M} \mathrm{K}_{2} \mathrm{HPO}_{4}$, and kept below $5^{\circ}$ for at least 10 minutes but not more than 60 minutes.

While still cool, $3 \mathrm{ml}$. of the supernatant liquid was then carefully removed from the precipitate of potassium perchlorate and mixed with $0.03 \mathrm{ml}$. of reduced nicotinamide-adenine dinucleotide solution ${ }^{1}\left(10^{-2} \mathrm{M}\right)$ in a $10 \mathrm{~mm}$. cuvette sealed with parafilm. The extinction was measured at $340 \mathrm{~m} \mu$ with a fixed slit width of $0.2 \mathrm{~mm}$.,

'This is now the approved name for diphosphopyridine nucleotide. using the sensitivity control for the zero extinction reading. The measurement was made against an arbitrary blank of $3 \mathrm{ml}$. of deionized water containing 0.01 to $\overline{0}$ $0.02 \mathrm{ml}$. of reduced nicotinamide-adenine dinucleotide.

Exactly $0.03 \mathrm{ml}$. of lactic dehydrogenase solution ${ }^{2} \frac{\overline{\bar{C}}}{\overline{\mathrm{D}}}$ $\left(0.75 \mathrm{mg} . / \mathrm{ml}\right.$.) was mixed with the test solution by $\frac{\vec{\Phi}}{\Delta}$ inversion, after sealing the cuvette again with parafilm. $\varrho$ Extinction readings against the same blank were recorded $\%$ after 90 seconds and 120 seconds.

Blank and standard measurements were made in $\vec{\circ}$ exactly the same way by substituting deionized water, and $\vec{\omega}$ a standard pyruvic acid solution for blood in the above $\omega$ procedure.

The blank measurement, which was about 0.012 , was? subtracted from those of standards and unknown. As $\vec{G}$ the reaction between pyruvic acid and reduced nicotin- is amide adenine dinucleotide is stoichiometric, the pyruvic $\mathrm{G}$ acid concentration was proportional to the corrected fall $\bullet$ in extinction. With the Unicam SP500 spectrophotometer 윽 used, an extinction change of 0.100 corresponded to $a-$ concentration of $0.60 \mathrm{mg}$. of pyruvate per $100 \mathrm{ml}$. of $Z$ blood. Two corrections, however, were applied. As $3 \mathrm{ml}$. of blood contained only about $2.54 \mathrm{ml}$. of water, the volume of solution after deproteinization was $8.54 \mathrm{ml}$. instead of $9 \mathrm{ml}$., and therefore the observed result was multiplied by $\frac{8.54}{9}$. Also $3 \%$ was added to the observed result to correct as closely as possible for the loss of pyruvate (Huckabee, 1956) in the one-minute interval between withdrawing and deproteinizing the blood. These two corrections were incorporated into the factor $\overline{0}$ for converting extinction values to pyruvate concentration.

OBSERVATIONS ON THE METHOD

The solutions of reduced nicotinamide-adenine dinucleotide and lactic dehydrogenase were obtained in a test kit, but the method described here differs in several ways from that supplied with the reagents. These differences are summarized below, and the reasons for introducing them are discussed.

1 Blood, $3 \mathrm{ml}$., was deproteinized with $6 \mathrm{ml}$. instead of $3 \mathrm{ml}$. of $0.6 \mathrm{M}$ perchloric acid. This was to ensure more complete deproteinization and to provide enough supernatant solution for duplicate $\frac{D}{O}$ analyses. The concentration of the dipotassium hydrogen phosphate solution was raised from $1 \cdot 1 \mathrm{M}$ N to $1.5 \mathrm{M}$ to produce the same $p \mathrm{H}$ in the buffer system as that which resulted when the smaller volume of perchloric acid was used.

2 The concentrations of reduced nicotinamide- $\mathcal{O}$ adenine dinucleotide and lactic dehydrogenase in the $\stackrel{\circ}{\circ}$ cuvettes were decreased by $60 \%$, and a blank $\bar{\Phi}$ determination was included with each series of $\stackrel{?}{?}$ unknowns. These changes were made because of the $T$ errors due to the fall in extinction which resulted $\stackrel{0}{\mathbb{D}}$ from dilution of the reduced nicotinamide-adenine $\stackrel{\bigcirc}{\Phi}$

${ }^{2} \mathrm{C}$. F. Boehringer and Soehne, Mannheim, Germany: Pyruvate testkit TC-C. 
dinucleotide by the added lactic dehydrogenase, in addition to the fall resulting from its oxidation. This was particularly large using the volume of reagents proposed by the suppliers, especially as the concentration of nicotinamide-adenine dinucleotide was found to be three times as great as that stated. Using the volumes stated above, neglecting to correct for the dilution of nicotinamide-adenine dinucleotide would have caused errors of about $0.07 \mathrm{mg} . / 100 \mathrm{ml}$. The introduction of a blank assay corrected for the dilution effect but errors could still result from"small variations in the volume of enzyme solution added. The reduction in the volume of each of the two reagents used did not impair the ability of the method to measure even quite high levels of pyruvate and produced a corresponding reduction in the errors which could arise from unreproducibility of volume measurement. The reduced nicotinamide-adenine dinucleotide available was equivalent to about $3.5 \mathrm{mg}$. of pyruvic acid per $100 \mathrm{ml}$. of blood, and the equilibrium constant of the reaction favoured maximum utilization. Accurate results were obtained on standard solutions corresponding to $3 \mathrm{mg}$. per $100 \mathrm{ml}$. of blood. If necessary for the measurement of higher levels, the deproteinized blood can be diluted with $0.4 \mathrm{M}$ perchloric acid before adding phosphate.

3 Volumes were adjusted to provide the $3 \mathrm{ml}$. of solution required by the $10 \mathrm{~mm}$. cuvettes of the Unicam SP500 spectrophotometer, and an instrument blank was prepared by diluting 0.01 to $0.02 \mathrm{ml}$. of the nicotinamide-adenine dinculeotide solution in $3 \mathrm{ml}$. of water. This avoided using the less accurate regions of the extinction scale for the measurement of changes in extinction.

4 A standard was included with each series of unknowns, and in all cases readings were taken 1.5 minutes, as well as two minutes, after adding the enzyme. These precautions were included to check the reagents and confirm that the reaction proceeded at its usual rate. When the correct values for the results of blank and standard assays had been established on numerous occasions, they were then used as a check on the performance of the method subsequently. The extinction readings two minutes after adding lactic dehydrogenase were not more than 0.003 lower than the readings 1.5 minutes after the addition. Larger differences usually indicated contamination of reagents, and the purpose of the 1.5 minute reading was to check that the reaction was by then almost complete. This was less timeconsuming than taking several readings at oneminute intervals after two minutes, as others have suggested.

We found that inadequate cooling of the blood during deproteinization with perchloric acid resulted in loss of pyruvic acid, due to persistence of lactic dehydrogenase activity until deproteinization was complete. Once deproteinization was completed, however, the pyruvate in the supernatant solution was stable for at least 24 hours, as demonstrated below. Single analyses were made on each of 17 blood samples. The residual deproteinized solution was left in the centrifuge tube in contact with the precipitated protein, and a second portion was used for analysis the following day. The result on the second day was not significantly different, being an average of $0.01 \mathrm{mg} . / 100 \mathrm{ml}$. higher than on the first day. The mean difference, ignoring sign, and the standard deviation calculated from these data, were each $0.04 \mathrm{mg} . / 100 \mathrm{ml}$, similar in fact to the values reported below for duplicates carried out both on the same day.

Errors also resulted if the temperature of the solution was allowed to exceed $5^{\circ} \mathrm{Cduring}$ the precipitation of potassium perchlorate, or if the deproteinized blood was not cooled before adding the phosphate. Thus, if the temperature was $8^{\circ}, 10 \%$ of the pyruvate was lost even within the minimum precipitation period of 10 minutes. This was thought to be due to renewed lactic dehydrogenase activity at higher temperatures, after the precipitation of the perchlorate, as the losses occurred with blood samples but not with standard solutions. Provided the temperature of the solution was kept below $5^{\circ}$ during precipitation of potassium perchlorate, a delay of 60 minutes did not significantly alter the level of pyruvate.

The precision of the method was investigated by inspecting the results of duplicate analyses. These are reported in Table $I$ for each of three analysts and show a standard deviation for the method of $0.03 \mathrm{mg} . / 100 \mathrm{ml}$. Single analyses on 13 samples were carried out by two analysts each of whom was unaware of the other's results. The mean result was the same for each analyst, indicating the absence of any systematic difference. Disregarding the sign of each difference, random errors yielded a standard

\section{TABLE I}

MEAN DIFFERENCES BETWEEN DUPLICATE RESULTS AND STANDARD DEVIATIONS FOR REPLICATE RESULTS CALCULATED FROM THE DIFFERENCES

\begin{tabular}{lccc} 
Analyst & No. of Analyses & $\begin{array}{l}\text { Mean } \\
\text { Difference }\end{array}$ & $\begin{array}{c}\text { Standard } \\
\text { Deviation }\end{array}$ \\
\hline 1 & 32 & 0.03 & 0.03 \\
2 & 26 & 0.04 & 0.04 \\
3 & 11 & 0.02 & 0.02 \\
2 and $3^{1}$ & 13 & 0.04 & 0.04 \\
Total & 82 & 0.03 & 0.03
\end{tabular}

${ }^{1}$ One of each pair of results was obtained by analyst 2 and the other by analyst 3. 
deviation of $0.04 \mathrm{mg} . / 100 \mathrm{ml}$., no greater than that obtained when one of the analysts made both measurements.

In carrying out recovery experiments, standard pyruvic acid was not added to blood before it had been mixed with perchloric acid, because of the consequent losses which would have occurred. In eight experiments, therefore, pyruvic acid was added to one of two portions of perchloric acid, to each of which portions of blood were then added simultaneously. The amount added corresponded to an increment of $1 \mathrm{mg}$. per $100 \mathrm{ml}$. of blood. The mean recovery was $99 \%$ and the standard deviation was $4 \%$.

\section{OBSERVATIONS ON THE COLLECTION OF SAMPLES}

Venepuncture is facilitated by warming the hand, repeated hand clenching, or venous occlusion. As importance is often attached to the avoidance of artefacts which might influence the pyruvate concentration during the collection of blood, the effect of each of these was investigated in fasting and nonfasting subjects.

In seven experiments the skin temperature of one hand was heated to 5 to $10^{\circ} \mathrm{C}$. above the temperature of the other, for at least 30 minutes, and blood was taken simultaneously from the antecubital fossa of each arm. The blood pyruvate concentration for the heated arm was an average of $0.01 \mathrm{mg} . / 100 \mathrm{ml}$. lower than that for the other (S.D. $0.07 \mathrm{mg} . / 100 \mathrm{ml}$.) and this difference was not statistically significant $(0 \cdot 1<P)$. In only two of the seven experiments was the difference greater than $0.03 \mathrm{mg} . / 100 \mathrm{ml}$.
In seven other experiments, blood pyruvate concentration was measured before and immediately $\stackrel{9}{\stackrel{9}{9}}$ following a period of $\mathbf{4 0}$ to $\mathbf{8 0}$ seconds of fist clench- $\bar{O}$ ing performed at the rate of one clench per second. The pyruvate concentration in the second sample was an average of $0.08 \mathrm{mg} . / 100 \mathrm{ml}$. higher than in the first (S.D. $0 \cdot 10 \mathrm{mg} . / 100 \mathrm{ml}$.). The mean change was not statistically significant $(0.05<P<0.1)$ and the degree of change did not appear to be related to the variation in clenching time.

In a further nine experiments the blood pyruvate concentration was measured before and after three minutes of venous occlusion by means of a sphygmo- $\overrightarrow{0}$ manometer cuff around the upper arm adjusted to a o pressure midway between the patient's systolic and $\dot{ }$ ' diastolic blood pressure. The pyruvate concentration $\sigma$ in the second sample was an average of $0.01 \mathrm{mg}$./ 은 $100 \mathrm{ml}$. lower than in the first sample (S.D. $0.11 \mathrm{mg}$./ $100 \mathrm{ml}$.) and this difference was not statistically significant $(0 \cdot 1<\mathrm{P})$.

\section{RESULTS}

BLOOD PYRUVATE CONCENTRATION IN FASTED SUBJECTS The pyruvate concentration was estimated ? in 75 venous blood samples from 30 fasted subjects. The mean level was $0.44 \mathrm{mg} . / 100 \mathrm{ml}$. (S.D. 0.05) with a range of 0.36 to $0.59 \mathrm{mg} . / 100 \mathrm{ml}$. In subjects for whom several results were obtained, the variability for the individual was as great as the variability between individuals. The results showed no significant difference between the sexes, the mean value being $0.46 \mathrm{mg} . / 100 \mathrm{ml}$. for the men, and $0.43 \mathrm{mg} . / 100 \mathrm{ml}$. for the women. There was no

TABLE II

RESPONSE OF VENOUS BLOOD PYRUVATE AND SUGAR LEVELS TO ORAL GLUCOSE

(1 g./kg. BODY WEIGHT) IN 15 FASTED CONTROLS

\begin{tabular}{|c|c|c|c|c|c|c|c|c|c|c|}
\hline \multirow[t]{3}{*}{ Subject } & \multicolumn{5}{|c|}{ Blood Pyruvate (mg./100 ml.) } & \multicolumn{5}{|c|}{ Blood Sugar (mg./100 ml.) } \\
\hline & \multicolumn{5}{|c|}{ Minutes after Glucose Administration } & \multicolumn{5}{|c|}{ Minutes after Glucose Administration } \\
\hline & 0 & 30 & 60 & 90 & 120 & 0 & 30 & 60 & 90 & 120 \\
\hline 1 & 0.37 & 0.78 & 0.70 & 0.83 & 0.70 & 75 & 118 & 120 & 126 & 110 \\
\hline 2 & $0 \cdot 37$ & 0.87 & 0.95 & 0.96 & 0.73 & 80 & 115 & 140 & 100 & 75 \\
\hline 3 & 0.38 & 0.67 & 0.96 & 0.89 & 0.63 & 90 & 115 & 160 & 150 & 110 \\
\hline 4 & 0.40 & 0.51 & $1 \cdot 19$ & 1.01 & 0.84 & 70 & 170 & 196 & 130 & 74 \\
\hline 5 & 0.41 & 0.42 & 0.68 & 0.78 & 0.73 & 85 & 120 & 156 & 130 & 112 \\
\hline 6 & 0.41 & 0.43 & 0.62 & 0.65 & 0.52 & 75 & 135 & 110 & 107 & 75 \\
\hline 7 & 0.42 & 0.45 & 0.76 & $1 \cdot 26$ & 0.84 & 90 & 130 & 174 & 150 & 120 \\
\hline 8 & 0.43 & 0.54 & 0.53 & 0.86 & 0.75 & 95 & 170 & 196 & 160 & 105 \\
\hline 9 & 0.43 & 0.58 & 1.06 & 0.66 & 0.59 & 82 & 120 & 110 & 100 & 80 \\
\hline 10 & 0.44 & 0.52 & 0.73 & 0.86 & 0.72 & 70 & 118 & 132 & 115 & 105 \\
\hline 11 & 0.47 & 0.53 & 0.77 & 0.54 & 0.52 & 75 & 108 & 135 & 110 & 98 \\
\hline 12 & 0.47 & 0.62 & 0.73 & 0.73 & 0.78 & 76 & 110 & 150 & 132 & 118 \\
\hline 13 & 0.47 & 0.63 & 0.91 & 1.00 & 0.88 & 82 & 114 & 160 & 150 & 108 \\
\hline 14 & 0.47 & 0.82 & 0.93 & 0.78 & 0.53 & 85 & 135 & 180 & 90 & 60 \\
\hline 15 & 0.50 & 0.51 & 0.97 & 0.89 & 0.83 & 115 & 155 & 170 & 160 & 112 \\
\hline Mean & 0.43 & 0.59 & 0.83 & 0.85 & 0.71 & & & & & \\
\hline S.D. & 0.04 & 0.14 & 0.19 & 0.18 & 0.11 & & & & & \\
\hline
\end{tabular}


significant variation of the venous blood levels of pyruvate with age. The mean value for the seven subjects under 25 years of age was the same as for the 11 subjects over 50 years of age, namely, $0.46 \mathrm{mg}$./ $100 \mathrm{ml}$., while the mean blood pyruvate level for the remaining 12 subjects, between 25 and 50 years of age, was $0.42 \mathrm{mg} . / 100 \mathrm{ml}$.

EFFECT OF ORAL GLUCOSE ON BLOOD PYRUVATE CONCENTRATION Glucose was given orally to 15 fasted subjects and the venous blood pyruvate and sugar levels were measured at 30-minute intervals for two hours. The results are reported in Table II. In all cases the oral glucose tolerance curve was within normal limits.

The mean blood pyruvate curve for these 15 subjects is shown in Fig. 1. From a mean fasting level of $0.43 \mathrm{mg} . / 100 \mathrm{ml}$. the mean pyruvate level rose by nearly $100 \%$ to $0.85 \mathrm{mg} . / 100 \mathrm{ml}$. and then fell to $0.71 \mathrm{mg} . / 100 \mathrm{ml}$. two hours after glucose administration. The highest level of blood pyruvate found was 60 minutes after glucose administration in six subjects, after 90 minutes in eight subjects, and after 120 minutes in the remaining subject.

EFFECT OF INTRAVENOUS GLUCOSE ON BLOOD PYRUVATE CONCENTRATION Glucose was given to 15 fasted subjects by intravenous injection. Venous blood samples were taken at 30-minute intervals for two hours for the measurement of pyruvate and at 15minute intervals for two hours for the measurement of sugar. The results reported in Table III show that intravenous glucose tolerance was normal in all cases.

The mean blood pyruvate curve for these 15

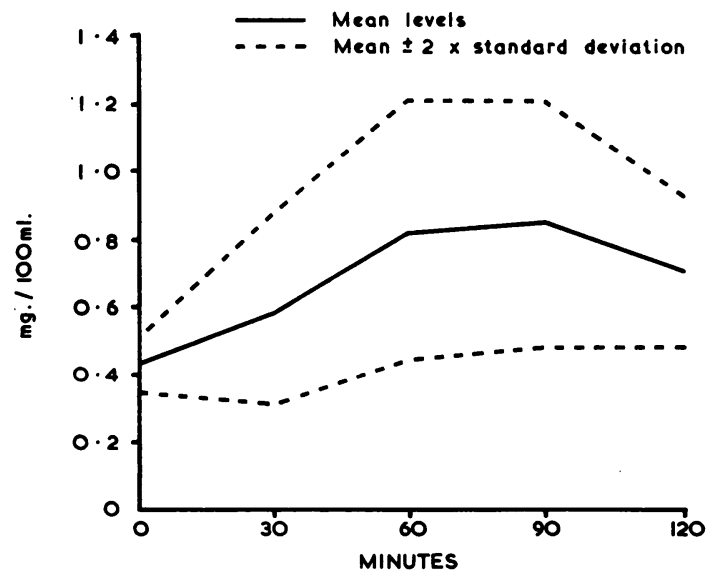

FIG. 1. Blood pyruvate levels after the oral administration of glucose. subjects is shown in Fig. 2. From a fasting level of $0.43 \mathrm{mg} . / 100 \mathrm{ml}$. the mean pyruvate level rose by nearly $100 \%$ to $0.82 \mathrm{mg} . / 100 \mathrm{ml}$. and then fell to $0.50 \mathrm{mg} . / 100 \mathrm{ml}$. two hours after glucose administration. The highest level of blood pyruvate was found 30 minutes after glucose administration in eight subjects and after 60 minutes in the remaining seven subjects.

\section{DISCUSSION}

The measurement of pyruvate as its hydrazone gives higher values than those obtained using specific methods, as the hydrazones of other $\alpha$-keto acids are also partially measured (Bauer, 1956). Thus, using a hydrazone method, Bueding and Wortis (1940) found a mean blood pyruvate level of $0.98 \mathrm{mg} . / 100 \mathrm{ml}$. (S.D. 0.09) in 60 fasted subjects compared with $0.44 \mathrm{mg} . / 100 \mathrm{ml}$. (S.D. 0.05 , range 0.36 to 0.59 ) found in the present study. Using the nicotinamide-adenine dinucleotide reaction for the specific measurement of blood pyruvate in normal fasted subjects, the mean value obtained by Bauer (1956) was $0.53 \mathrm{mg} . / 100 \mathrm{ml}$. (range 0.30 to 0.81 ), by Redetzki et al. (1956) $0.57 \mathrm{mg} . / 100 \mathrm{ml}$. (S.D. 0.16), by Segal et al. (1956) $0.66 \mathrm{mg} . / 100 \mathrm{ml}$. (range 0.39 to 0.86 ), and by Tsirimbas and Stich (1960) $0.56 \mathrm{mg}$./ $100 \mathrm{ml}$. (S.D. 0.11). These results are higher than those we obtained, possibly because the other workers did not subtract a blank reading to allow for the fall in reduced nicotinamide-adenine dinucleotide extinction due to dilution by lactic dehydrogenase. The range and standard deviation obtained by these workers are also larger than in the present study.

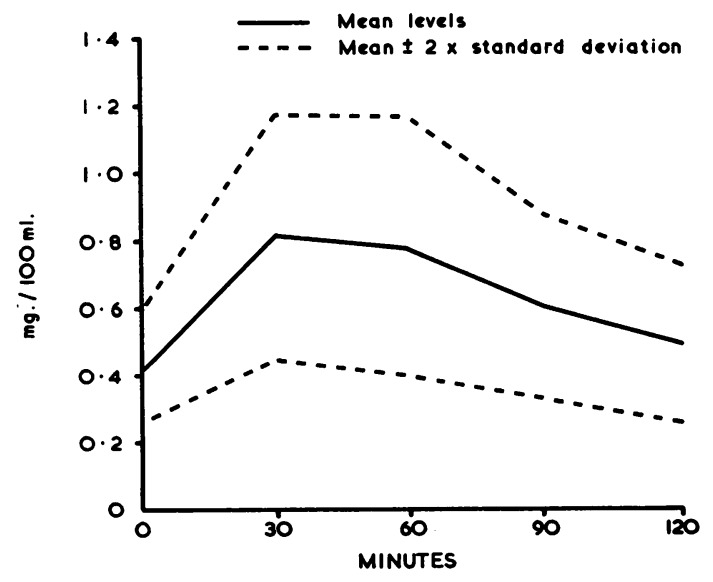

FIG. 2. Blood pyruvate levels after the intravenous administration of glucose. 
TABLE III

RESPONSE OF VENOUS BLOOD PYRUVATE AND SUGAR LEVELS TO INTRAVENOUS GLUCOSE

$(0.5$ g./ $\mathrm{kg}$. BODY WEIGHT) IN 15 FASTED CONTROLS

Subject Blood Pyruvate (mg./100 ml.)

\begin{tabular}{clllll}
\multicolumn{5}{c}{ Minutes } & \multicolumn{5}{l}{ after Glucose } & \multicolumn{4}{l}{ Administration } \\
\cline { 2 - 6 } & 0 & 30 & 60 & 90 & 120 \\
\hline 1 & 0.35 & 0.66 & 0.83 & 0.54 & 0.29 \\
2 & 0.35 & 0.95 & 1.13 & 0.79 & 0.54 \\
3 & 0.36 & 0.58 & 0.70 & 0.64 & 0.60 \\
4 & 0.38 & 0.87 & 0.95 & 0.86 & 0.73 \\
5 & 0.39 & 0.81 & 0.39 & 0.35 & 0.33 \\
6 & 0.39 & 0.90 & 0.82 & 0.65 & 0.61 \\
7 & 0.42 & 0.62 & 0.72 & 0.63 & 0.38 \\
8 & 0.42 & 0.94 & 0.84 & 0.51 & 0.53 \\
9 & 0.43 & 0.62 & 0.65 & 0.56 & 0.52 \\
10 & 0.44 & 0.62 & 0.63 & 0.57 & 0.41 \\
11 & 0.44 & 1.13 & 1.04 & 0.58 & 0.40 \\
12 & 0.46 & 0.93 & 0.77 & 0.62 & 0.50 \\
13 & 0.49 & 0.83 & 0.73 & 0.48 & 0.44 \\
14 & 0.53 & 1.11 & 1.02 & 0.87 & 0.77 \\
15 & 0.65 & 0.84 & 0.57 & 0.52 & 0.47 \\
Mean & 0.43 & 0.82 & 0.79 & 0.61 & 0.50 \\
S.D. & 0.08 & 0.18 & 0.19 & 0.14 & 0.12
\end{tabular}

Several workers (Bueding, Wortis, and Fein, 1942; Klein, 1942; Bueding and Goldfarb, 1943; Joiner, McArdle, and Thompson, 1950; Shrifter and Kritzer, 1956) found a transient rise in the blood pyruvate concentration after glucose loading, and found abnormalities of the pyruvate curve after glucose in several diseases, for example, diabetes mellitus and thiamine deficiency. These workers used non-specific hydrazone methods for the measurement of the blood pyruvate. The pyruvate levels after glucose have also been measured by a more specific chromatographic modification (Thompson, Butterfield, and Fry, 1960; McArdle, Mackenzie, and Webster, 1960).

We are not aware of any report on the changes in blood pyruvate concentration, measured by the specific reduced nicotinamide-adenine dinucleotide reaction, after the oral and intravenous administration of glucose to control subjects. The results presented here will be used in the interpretation of results, to be reported later, obtained from patients with conditions which may affect pyruvate metabolism.

We thank Miss G. Robertson who carried out many of the analyses and Mr. H. D. Philps who kindly translated the relevant German literature. One of us (J.L.) gratefully

\begin{tabular}{|c|c|c|c|c|c|c|c|}
\hline \multicolumn{8}{|c|}{ Minutes after Glucose Administration } \\
\hline 0 & 30 & 45 & 60 & 75 & 90 & 105 & 120 \\
\hline 74 & 186 & 160 & 139 & 115 & 104 & 85 & 70 \\
\hline 75 & 176 & 130 & 100 & 80 & 75 & 60 & 65 \\
\hline 80 & 195 & 158 & 120 & 100 & 80 & 76 & 70 \\
\hline 85 & 249 & 211 & 160 & 130 & 110 & 96 & 90 \\
\hline 85 & 245 & 197 & 158 & 130 & 100 & 90 & 80 \\
\hline 95 & 192 & 158 & 128 & 113 & 100 & 70 & 75 \\
\hline 76 & 204 & 153 & 118 & 98 & 80 & - & - \\
\hline 71 & 201 & 153 & 128 & 108 & 81 & - & 60 \\
\hline 70 & 255 & 202 & 154 & 129 & 114 & - & 96 \\
\hline 75 & 195 & 149 & 114 & 81 & 80 & 80 & 75 \\
\hline 80 & 200 & 160 & 132 & 118 & 95 & 90 & 80 \\
\hline 80 & 210 & 153 & 121 & 104 & 80 & 72 & 70 \\
\hline 85 & 188 & 149 & 110 & 88 & 75 & 70 & 66 \\
\hline 85 & 200 & 160 & 124 & 96 & 80 & 80 & 76 \\
\hline 75 & 168 & 129 & 98 & 90 & 70 & - & 75 \\
\hline
\end{tabular}

acknowledges financial support by the Medical Research Council.

\section{REFERENCES}

Barrenscheen, H. K., and Dreguss, M. (1931). Biochem. Z., 233, 305. Bauer, H. (1956). Ibid., 327, 491.

Bonting, S. L. (1955). Arch. Biochem., 58, 100.

Bueding, E., and Goldfarb, W. (1943). J. biol. Chem., 147, 33. _- and Wortis, H. (1940). Ibid., 133, 585.

- _ - _, and Fein, H. D. (1942). Amer. J. med. Sci., 204, 838.

Cavallini, D., Frontali, N., and Toschi, G. (1949). Nature (Lond.), (1) $163,568$.

El Hawary, M. F. S., and Thompson, R. H. S. (1953). Biochem. J., 53,340 .

Friedemann. T. E., and Haugen, G. E. (1943). J. biol. Chem., 147, 415.

Hess, B. (1955). Klin. Wschr., 33, 540.

Huckabee, W. E. (1956). J. appl. Physiol., 9, 163

Joiner, C. L., McArdle, B., and Thompson, R. H. S. (1950). Brain 73,431 .

Klein, D. (1941). J. biol. Chem., 137, 311.

(1942). Ibid., 145, 35.

Kubowitz, F., and Ott, P. (1943). Biochem. Z., 314, 94.

Lu, G. D. (1939). Biochem. J., 33, 249.

McArdle, B. (1957). Ibid., 66, 144.

_- Mackenzie, I. C. K., and Webster, G. R. (1960). J. Neurol.o Neurosurg. Psychiat., 23, 127.

Redetzki, H., Bloedorn, H., and Bansi, H. W. (1956). Klin. Wschr. D 34,845 . 34, 845.
Segal, S., Blair, A. E., and Wyngaarden, J. B. (1956). J. Lab. clin. Med.

Seligson, D., and Shapiro, B. (1952). Analyt. Chem., 24, 754.

Shrifter, N., and Kritzer, M. D. (1956). A.M.A. Arch. intern. Med.N

98, 28.
Thompson, R. H. S., Butterfield, W. J. H., and Fry, I. K. (1960) $\mathrm{W}$ Proc, roy. Soc. Med., 53, 143.

Tsirimbas, A., and Stich, W. (1960). Klin. Wschr., 38, 1196. 